\title{
Modified geometry three-layered tablet as a platform for class II drugs zero-order release system
}

\author{
Abdullah Monahi Albogami, Mustafa E Omer, Abdulkareem M Al Bekairy, \\ Abdulmalik Alkatheri and Alaa Eldeen B Yassin* \\ College of Pharmacy, King Saud bin Abdulaziz University for Health Sciences, King Abdullah International Medical Research \\ Center, and King Abdulaziz Medical City, Ministry of National Guard, Health Affairs, Riyadh, Saudi Arabia
}

*For correspondence: Email: yassina@ksau-hs.edu.sa; Tel: +966509426323; Fax: +966114299999\#95058

Sent for review: 7 April 2017

Revised accepted: 25 July 2017

\begin{abstract}
Purpose: To optimize a geometrical design of three-layered tablets for controlling the release of indomethacin (Ind) as a BCS class II model.

Methods: The core formulation was optimized to ensure non-disintegrating tablet with a slow release behavior. Three-layered tablets were prepared by a single-step direct compression method by manual feeding of a hydrophobic layer in the bottom followed by Ind core layer and another hydrophobic layer at the top using 6 and $12 \mathrm{~mm}$ round compression sets. Four batches were prepared, differing only in either thickness of the drug layer or tablet diameter. A number of factors were studied, including tablet thickness to diameter ratio and drug layer surface area. The rate of Ind released was determined using USP dissolution apparatus I.

Results: The optimum drug layer formulation contained Ind (40\%), polyvinylpyrolidone K30 (40\%), and ethyl cellulose $(20 \%)$. The t50\% (time taken for $50 \%$ drug release) for the four three-layered tablet batches with varying diameter to thickness ratios were in the range of 1.5 to $3.7 \mathrm{~h}$. The diameter to thickness ratios were in good correlation with \% Ind release after $4 h(R 2=0.94)$. It was found that all batches complied with zero order kinetic model.

Conclusion: The new one-compression phase applied in this study is successful in producing threelayered tablets in a single-step with very good mechanical attributes. The approach of designing a controlled release tablet via control of the surface area of drug release is feasible for non-swelling matrices.
\end{abstract}

Keywords: Controlled release, Indomethacin, BCS class II drugs, Ethyl cellulose, Release kinetics, Direct compression

Tropical Journal of Pharmaceutical Research is indexed by Science Citation Index (SciSearch), Scopus, International Pharmaceutical Abstract, Chemical Abstracts, Embase, Index Copernicus, EBSCO, African Index Medicus, JournalSeek, Journal Citation Reports/Science Edition, Directory of Open Access Journals (DOAJ), African Journal Online, Bioline International, Open-J-Gate and Pharmacy Abstracts

\section{INTRODUCTION}

The ultimate goal of oral controlled drug delivery systems is to maintain therapeutic drug blood levels almost constant for a certain period of time after per-oral administration [1,2]. Minimizing adverse effects associated with high plasma drug concentration, reducing the frequency of dosing, and higher patient compliance are considered the major advantages of oral controlled release systems [1]. Despite the huge number of marketed oral controlled release products, only three approaches are employed including matrix, reservoir, osmotic, or ion exchange [3]. Multilayered tablets and technologies such as Geomatrix ${ }^{\circledR}$ and Smartrix ${ }^{\circledR}$ are considered typical examples of correlating the system dimensions with the release behavior [4-6]. These systems were able to achieve kinetic models close to zero-order release kinetics from hydrophilic 
matrix tablets $[7,8]$. The key factor in the design of such systems is to maintain a constant surface area available for drug release $[9,10]$.

Multi-layered tablets have showed a growing attention as a useful controlled release tool with multiple other applications such as drug combinations with reduced chance of interaction and/or inducing multi-drug release profiles in one dosage form [11].

Sandwich-like three-layered tablets with drug core middle layer and two barrier layers is more reliable for constant rate release purpose. The main factors that affect the performance of such system are the nature and ratio of both the barrier and core layers and the geometrical design of the tablet [12]. Hydrophilic polymers such as hydroxyl propyl cellulose (HPC) and polyethylene oxide (PEO) and the hydrophobic polymer such as cellulose acetate propionate (CAP) and ethyl cellulose (EC) are possible candidates for the barrier layer. The incorporation of a release retarding polymer in the core layer can also be employed in certain designs. Geometric factors such as the core thickness or ratio of core thickness to diameter are the main design related parameters that are usually manipulated for optimization [13].

This study aims to optimize a three-layered tablet as geometrically controlled release system for Ind, a model drug for Biopharmaceutical Classification System (BCS class II).

\section{EXPERIMENTAL}

\section{Materials}

Indomethacin, Avicel PH101, starch 1500, magnesium stearate, HPMC K100, K1500, $\mathrm{K} 4000$, ethylcellulose, polyvinylpyrolidone, and talc were purchased from Sigma-Aldrich Chemical Co. (St Louis, MO, USA). All other reagents and chemicals were of analytical grade.

\section{Preparation of the core tablet}

The core tablet formula was first optimized to give a good integrity, mechanical, and Ind release controlling properties. Direct compression method was employed and various compositions were attempted. Various combinations of excipients in varying ratios were tried including, anhydrous lactose, Avicel Ph101, polyvinylpyrolidone (PVP), HPMC and ethylecellulose. A formula containing Ind (40\%), ethylecellulose $(20 \%)$, magnesium steararte $(1$ $\%)$, and PVP (39\%) showed optimum properties and were employed for the preparation of the three-layered tablets.

\section{Preparation of three-layered tablets}

Three-layered tablets were prepared by a singlestep direct compression method by manual feeding of a hydrophobic barrier layer in the bottom followed by Ind core layer and another hydrophobic barrier layer at the top. Two round compression sets; $6 \mathrm{~mm}$ and $12 \mathrm{~mm}$ were used. Both the upper and bottom layers were composed of EC containing $1 \%$ of magnesium stearate. Four batches were prepared differing only in either thickness of the drug layer or the tablet diameter. Table 1 shows the exact composition of each batch. Number of factors was studied including, tablet thickness to diameter ratio and the drug layer surface area.

\section{Evaluation of prepared three-layered tablets}

All the prepared three-layered tablets formulae were evaluated for the uniformity of the tablets and barrier layers thickness and the in vitro release characteristics.

\section{Uniformity of thickness}

The thickness of 10 three-layered tablets were individually measured using a micrometer, and the thickness of each barrier layer in each of the 10 tablets was also determined.

\section{In vitro release}

The drug release profile from each of the prepared three-layered tablet formula will be monitored by placing a sample of three tablets in USP dissolution apparatus II (Paddle method) in phosphate buffer $\mathrm{pH} 7.2$ at $37^{\circ} \mathrm{C} \pm 0.5$ applying a rotating speed of $50 \mathrm{rpm}$.

Table 1: Composition of the prepared tablet formulations

\begin{tabular}{lcccc}
\hline Variable & Batch 1 & Batch 2 & Batch 3 & Batch 4 \\
\hline Ind & $10 \mathrm{mg}$ & $20 \mathrm{mg}$ & $40 \mathrm{mg}$ & $80 \mathrm{mg}$ \\
EC & $5 \mathrm{mg}$ & $10 \mathrm{mg}$ & $20 \mathrm{mg}$ & $40 \mathrm{mg}$ \\
PVP & $10 \mathrm{mg}$ & $20 \mathrm{mg}$ & $40 \mathrm{mg}$ & $80 \mathrm{mg}$ \\
Top layer (EC) & $50 \mathrm{mg}$ & $50 \mathrm{mg}$ & $200 \mathrm{mg}$ & $200 \mathrm{mg}$ \\
Bottom layer (EC) & $50 \mathrm{mg}$ & $50 \mathrm{mg}$ & $200 \mathrm{mg}$ & $200 \mathrm{mg}$ \\
\hline
\end{tabular}


Samples of $5 \mathrm{~mL}$ were withdrawn manually at certain time intervals and replaced with fresh preheated (at $37^{\circ} \mathrm{C}$ ) dissolution medium. The amount of drug released will be determined spectrophotometrically at $\lambda_{\max }=320$ utilizing UV/VIS Spectrophotometer, Evolution 60S, (Thermo Scientific, USA). The standard calibration curve showed good linearity with $\mathrm{R}^{2}=$ 0.9983 and regression equation, $y=0.0076+$ 0.0635 .

\section{Kinetic analysis of release profiles}

To determine the release kinetic model and mechanisms, the dissolution data for each formula were analyzed using three kinetic models including the zero-order (Eq 1), HixonCrowell ( $\mathrm{Eq} 2$ ), and Higuchi ( $\mathrm{Eq} 3$ ) equations. The equation with the best fit was considered indicative for the kinetic model that best describes the release of the drug. In order to further investigate the release mechanism, the data were analyzed using Korsmeyer-Peppas equation ( $\mathrm{Eq} 4)$ and the value of the release exponent was used to confirm the kinetic model of release.

$$
\begin{aligned}
& M_{t} / M_{\infty}=K_{0} t \ldots \ldots \ldots \ldots \ldots \ldots \ldots \ldots(1) \\
& \left(1-M_{t} / M_{\infty}\right)^{1 / 3}=100^{1 / 3}-K_{x} t \ldots \ldots \ldots(2) \\
& M_{t} / M_{\infty}=k_{h} t_{1 / 2} \ldots \ldots \ldots \ldots \ldots \ldots \ldots \ldots(3) \\
& M_{t} / M_{\infty}=K_{p} t^{n} \ldots \ldots \ldots \ldots \ldots \ldots \ldots . .(4)
\end{aligned}
$$

where $M_{t} / M_{\infty}$ is the fraction of drug released from a tablet after time t. $\mathrm{K}_{0}, \mathrm{~K}_{\mathrm{x}}, \mathrm{k}_{\mathrm{h}}$, and $\mathrm{K}_{\mathrm{p}}$ are the rate constant of zero-order, Hixon-Crowell, Higuchi, and Korsmeyer-Peppas models and $n$ is the release exponent of the drug transport mechanism.

\section{Statistical analysis}

Difference between the drug cumulative amounts released from each tested tablet at each time point values (mean \pm SD) was carried out using one way analysis of variance (ANOVA), followed by an appropriate post hoc test in the case of presence of significant difference. $P<0.05$ will be taken as a criterion for a statistically significant difference.

\section{RESULTS}

The physical characteristics of each of the prepared batch are summarized in Table 2 . It is clear that all of the batches showed very good attributes with high hardness in the range of 100 $-110 \mathrm{~N}$ and very low friability values below 0.5
$\%$. They all showed elegant appearance as shown in Figure 1 with clearly definite drug core layer. The core layer thickness varied from 1 to $2.17 \mathrm{~mm}$. The thickness to diameter ratios were in the range from 0.09 to 0.32 .

Table 2: Some physical characteristics of the formulations

\begin{tabular}{lcccc}
\hline Parameter & Batch 1 & Batch 2 & Batch 3 & Batch 4 \\
\hline Hardness (N) & 110 & 107 & 105 & 101 \\
Friability $(\%)$ & 0.3 & 0.2 & 0.5 & 0.5 \\
Thickness (mm) & 1.0 & 1.02 & 1.9 & 2.17 \\
Diameter (mm) & 6.0 & 12.0 & 6.0 & 12.0 \\
\hline
\end{tabular}

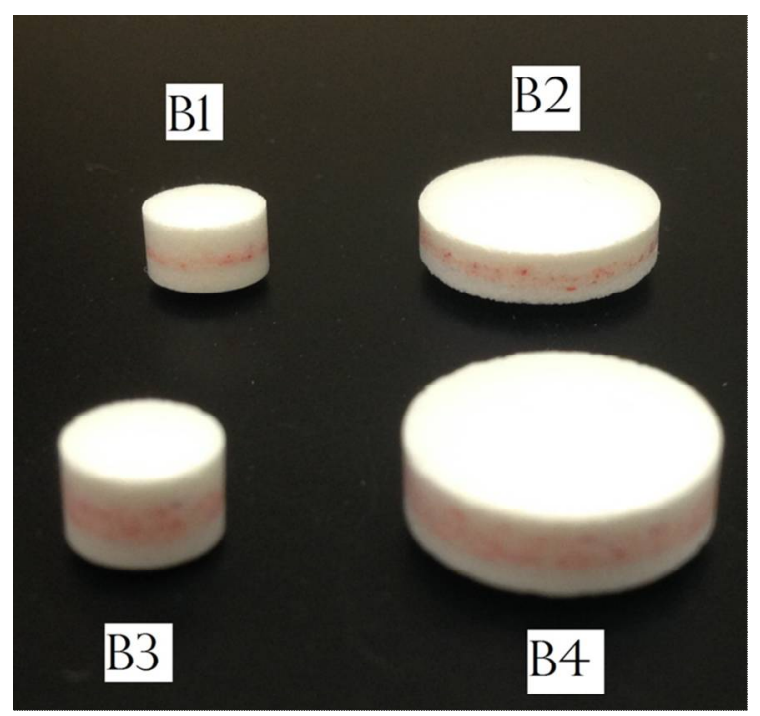

Figure 1: Photograph of a representative tablet from each of the prepared batches

The employed analytical method showed very high sensitivity for the determination of low concentrations of Ind. The standard calibration curve indicated high correlation in the range of concentrations from 10 to $50 \mu \mathrm{g} / \mathrm{ml}$ (Table 3).

The release profile of Ind from the four batches is presented in Figure 2. It is clear that all the four formulations exhibited a slow release profile with varying rate. B3 showed the fastest release among all the formulations while B2 was the slowest. The cumulative \% Ind released after $1 \mathrm{~h}$ were $19.9 \pm 1.2,12.17 \pm 1.5,36.18 \pm 3.2$ and $17.51 \pm 1.4 \%$ for B1, B2, B3, and B4, respectively. It is clear that only B3 showed relatively high burst release. The time needed for $50 \%$ Ind release was estimated to be 3.34, 3.72, 1.47, and $2.06 \mathrm{~h}$ for B1, B2, B3, and B4, respectively. After $4 \mathrm{~h}$, the cumulative \% Ind released reached $79.8 \pm 5.4 \%$ for $B 4,87.76 \pm$ $6.90 \%$ for B3, $55.36 \pm 14.90 \%$ for B2 and 62.81 $\pm 19.2 \%$ for B1.

Figure 3 shows a plot of the ratio of thickness to diameter against the cumulative \% Ind released 


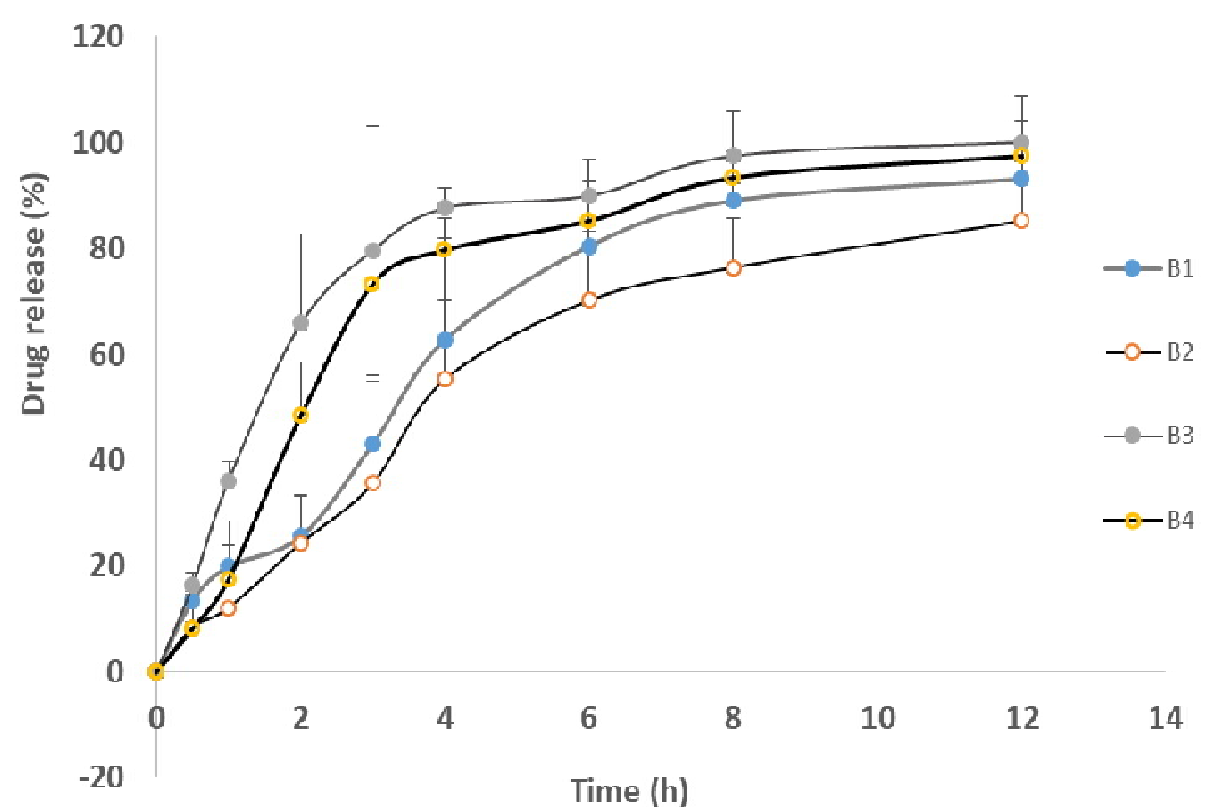

Figure 2: Cumulative percent released Indomethacin from four different geometrically modified-release tablets

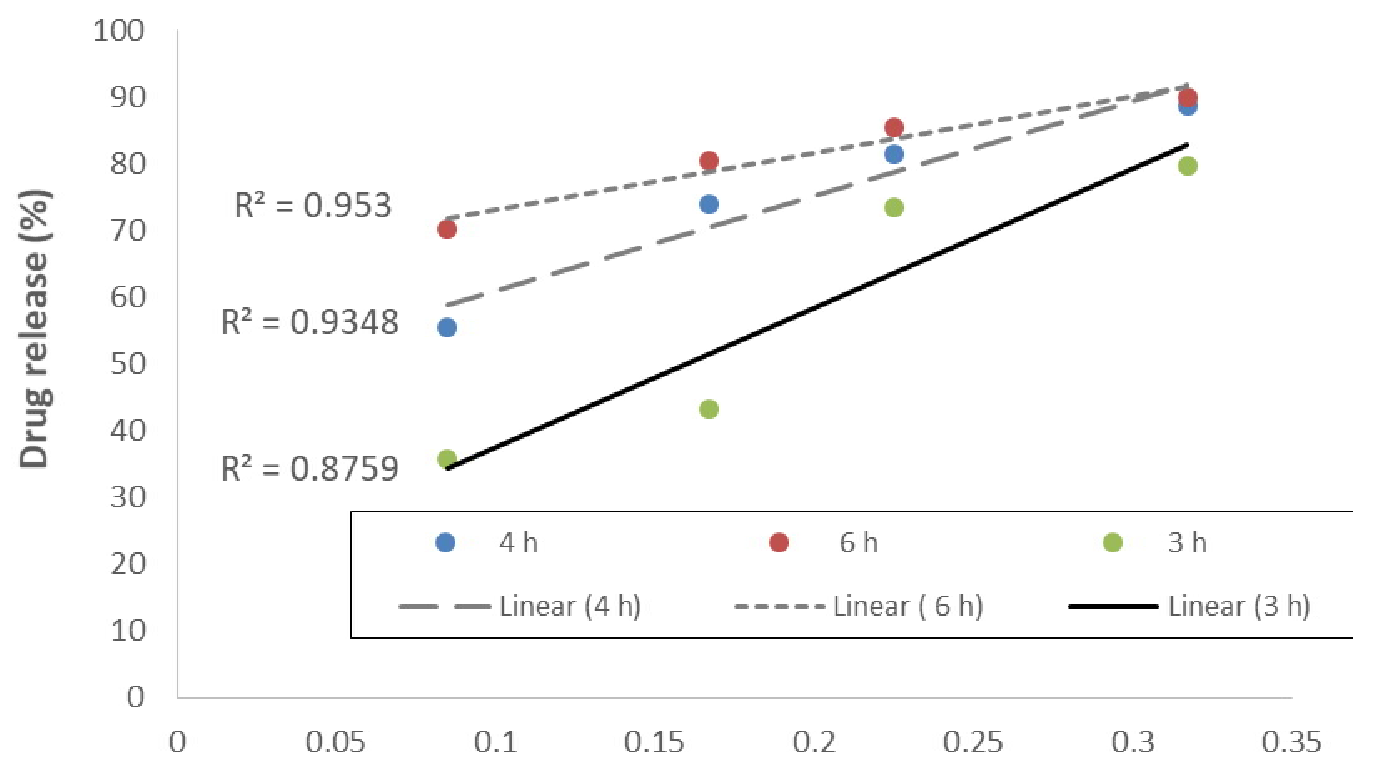

Thickness to Diameter ratio

Figure 3: Correlation between thickness/diameter ration with cumulative percent Ind released after 4 hours

Table 3: Correlation coefficients of various kinetic models and release exponents for Ind in three-layered tablet formulations

\begin{tabular}{lcccc}
\hline $\begin{array}{l}\text { Formulation } \\
\text { code }\end{array}$ & Zero order & Higuchi & Hixon-Crowell & $\begin{array}{c}\text { Korsmeyer-Peppas } \\
\text { exponent }(\mathbf{n})\end{array}$ \\
\hline B1 & 0.9634 & 0.9301 & 0.9614 & 0.8153 \\
B2 & 0.9513 & 0.9815 & 0.9898 & 0.8612 \\
B3 & 0.9868 & 0.9383 & 0.9601 & 0.9003 \\
B4 & 0.9281 & 0.9127 & 0.896 & 0.7281 \\
\hline
\end{tabular}

after 3, 4 and $6 \mathrm{~h}$. It is clear that the ratio of thickness to diameter is inversely proportional to the rate of drug release and as the ratio gets higher values the Ind release rate gets slower at the three time periods. The values of the squared regression were $0.88,0.93$, and 0.95 after 3,4 and $6 \mathrm{~h}$, respectively. This depicts the existence of high level of correlation between the ratio of 
thickness to diameter of the tablets and the \% of Ind released. The correlation is increasing with the increase in the release time.

Analysis of the drug release kinetics revealed higher $r$ values with both zero order and HixonCrowell models for all formulations except B4 which showed higher values with Zero order and Higuchi models. However the values of the Korsmeyer-Peppas model exponent, n, were all higher than 0.5 and below 1. This indicates a non-Fickian following an anomalous behavior.

\section{DISCUSSION}

It was proposed by Abdul and Poddar [14] and Qiu et al [15] that in order to achieve a linear drug release from a three-layered controlled release tablets, hydrophobic core layer and two hydrophilic barrier layers are necessary design. On the other hand, the triple-layered Geomatrix ${ }^{\circledR}$ tablets design showed a hydrophilic matrix core layer and two semipermeable hydrophobic barrier layers. However in our work, the core was a mixture of hydrophobic and hydrophilic polymers while the barrier layers were completely hydrophobic in nature.

Kim [16] described a three-layered donut-shape tablet composed of a core layer matrix made mainly of the enteric polymer hydroxypropyl methylcellulose acetate succinate and two barrier layers on either sides made of ethylcellulose. He showed that the system is capable of providing a constant zero-order release for a variety of drugs at $10 \%$ drug loading in the core layer. The $\mathrm{pH}$ dependency of the core layer is considered a limitation in this design compared with our proposed core layer composed of ethylcellulose and PVP.

Choi et al [17] introduced a novel design for a three-layered controlled release tablet composed of a hydrophilic middle layer and two barrier layers containing swellable hydrophilic polymers. The design allowed wrapping of the middle layer by the swelling of the barrier layers and drug release was through the barrier layers only. Key factors for the success of this system is the dimensions of the three layers and the nature and properties of the barrier layer polymers.

The high correlation between a dimensional factor in the design of the system and the release rate reflects the geometrical nature of the produced controlled release systems and the possibility of extrapolating this relation to prepare a system with specified intended release rate. Such correlation can be tailored toward designing many controlled release tablets with a variety of release rates.

The employed technique in producing a threelayered tablet in a single step compression is considered advantageous over the multiple compression tableting technique due to the high simplicity, the ease of application in pharmaceutical industry and better tablet physical quality.

\section{CONCLUSION}

The new one-compression phase introduced in this study has successfully produced threelayered controlled release tablets in a single-step with good mechanical attributes. The use of nonswelling drug release layer is useful for maintaining almost constant surface area all over the drug release period. This can be utilized in developing useful mathematical correlations and to predict the optimum design for any desired release rate.

\section{DECLARATIONS}

\section{Acknowledgement}

This work was supported by a grant from King Abdullah International Research Center, National Guard Health Affairs, Riyadh, Saudi Arabia (Grant no. SP14/071). The funding agency had no role in the study design, data collection and analysis, decision to publish, or preparation of the manuscript.

\section{Conflict of Interest}

No conflict of interest associated with this work.

\section{Contribution of Authors}

The authors declare that this work was done by the authors named in this article and all liabilities pertaining to claims relating to the content of this article will be borne by them.

\section{Open Access}

This is an Open Access article that uses a funding model which does not charge readers or their institutions for access and distributed under the terms of the Creative Commons Attribution License (http://creativecommons.org/licenses/by/ 4.0) and the Budapest Open Access Initiative (http://www.budapestopenaccessinitiative.org/rea d), which permit unrestricted use, distribution, and reproduction in any medium, provided the original work is properly credited. 


\section{REFERENCES}

1. Chen $X$, Wen $H$, Park $K$. Challenges and new technologies of oral controlled release, In: Wen $H$, Park $K$, Eds. Oral Controlled Release Formulation Design and Drug Delivery: Theory to Practice. New Jersey: Wiley \& Sons; 2010; pp 257-277.

2. Nair AB, Vyas H, Kumar A. 2010. Controlled release matrix uncoated tablets of enalapril maleate using HPMC alone. J Basic Clin Pharm 2010; 1(2): 71-75.

3. Wen H.; Park K. Introduction and overview of oral controlled release formulation design, In: Wen H.; Park, $K$, editors. Oral Controlled Release Formulation Design and Drug Delivery: Theory to Practice. New Jersey: Wiley \& Sons; 2010. P. 6.

4. Conte U, Maggi L, Colombo P, Manna L. Multilayered hydrophilic matrices as constant release devices. J. Control Release 1993; 26: 39-47.

5. Efentakis $M$, Politis S. Comparative evaluation of various structures in polymer controlled drug delivery systems and the effect of their morphology and characteristics on drug release. Eur Polym J 2006; 42: 1183-1195.

6. Yu D, Branford-White C, Ma Z, Zhu LM, Li XY, Yang XL. Novel drug delivery devices for providing linear release profiles fabricated by 3DP. Int J Pharm 2009; 370:160 166.

7. Ford JL, Rubenstein MH, McCaul F, Hogan JE, Edgar $P J$. Importance of drug type, tablet shape and added diluents on drug release kinetics from hydroxypropylmethylcellulose matrix tablets. Int J Pharm 1987; 40: 233-234.

8. Siepmann J, Streubel A, Peppas NA. Understanding and predicting drug delivery from hydrophilic matrix tablets using the "sequential layer" model. Pharm Res 2002; 19: 306-314.

9. Shah $A C$, Britten NJ. Novel divisible tablet designs for sustained release formulations, J. Control Release 1990; 14: 179-185.

10. Danckwerts MP. Development of a zero-order release oral compressed tablet with potential for commercial tableting production, Int J Pharm 1994; 112: 37-45.

11. Namdeo, B. Barrier layers in multilayered tablets. Express Pharma2008. Available online: www.expresspharmaonline.com/20080731/ research03. shtml (accessed on 11 March 2017).

12. Moodley K, Pillay V, Choonara Y, du Toit L, Ndesendo V, Kumar P, Cooppan S, Bawa P. 2012. Oral Drug Delivery Systems Comprising Altered Geometric Configurations for Controlled Drug Delivery. Int J Mol Sci 2012; 13: 1843.

13. Choi DH, Kim KH, Park JS, Jeong SH, Park K. 2013. Evaluation of drug delivery profiles in geometric threelayered tablets with various mechanical properties, in vitro-in vivo drug release, and Raman imaging. $J$ Control Rel 2013; 172: 763-772.

14. Abdul S, Poddar SS. A flexible technology for modified release of drugs: Multi layered tablets. J. Control. Release 2004; 97: 393-405.

15. Qiu Y, Chidambaram N, Flood K. Design and evaluation of layered diffusional matrices for zero-order sustainedrelease. J. Control. Release 1998: 51: 123-130.

16. Kim CJ. Controlled release from triple layer, donutshaped tablets with enteric polymers. AAPS PharmSci 2005; 6: 429-436.

17. Conte U, Maggi L. Modulation of the dissolution profiles from Geomatrix ${ }^{8}$ multi-layer matrix tablets, containing drugs of different solubility. Biomaterials 1996; 17: 889896 